\title{
The Use of Design Models of Wind-Electric Set with a Horizontal Axis of Rotation of the Wind Wheel for Dynamic Calculations at Urban Development
}

\author{
Igor Konstantinov ${ }^{1}$, Alexey Savchenko ${ }^{1}$, Artem Frolov ${ }^{1, a}$, Luka Akimov ${ }^{1}$ and Mihail Holmin ${ }^{1}$ \\ ${ }^{1}$ Peter the Great Saint-Petersburg Polytechnic University, 29 Polytechnicheskaya st., St.Petersburg, 195251, \\ Russian Federation
}

\begin{abstract}
The issues of modern urban development raise a significant question about an environmental cleanliness of progressing cities. Energy sources which are running on fuel cause tremendous harm to the atmosphere. Therefore, special attention is paid to the rational use of natural renewable resources such as wind and solar energy. Wind-electric sets, or wind turbines, are able to work autonomously, which is also important for the development of modern "smart" cities. Currently, the most commonly used design of wind turbines is the system which has the form of a tower of circular cross section (also called pipe), which carries at the upper end a nacelle with wind wheel. When such a system is being designed in urban conditions the wind pulsation and seismic calculations are added to the standard calculations. These added calculations are dynamic loads. It is known that in the process of solution of dynamic tasks design models of various levels of approximation can be used. It occurs due to stages of the design and other factors. The question of errors, which are associated with the use of a dissected, or partitioned, design scheme, raises.
\end{abstract}

\section{Introduction}

In today's urban construction it is very important to pay attention to renewable energy sources [1-4] because of their ability to harmless and autonomously supply power to rapidly developing progressing cities [5-7]. Multifactorial assessment of wind energy potential of urban development area allows to use the wind energy wisely [8]. One of the most commonly used renewable energy sources is wind turbine which has the form of a tower of circular cross section (also called pipe), which carries at the upper end a nacelle with wind wheel. The wind wheel has two or three blades and it is rotated about a horizontal axis or an axis deviated from the horizontal by a small angle (in one type of the windelectric set called "Raduga" this angle is $5^{\circ}$ ). The lower end of the tower rests on massive reinforced

${ }^{\mathrm{a}}$ Corresponding author: artemfrolov007@mail.ru 
concrete foundation or reinforced concrete grillage of pile foundation, which is relying on the subgrade.

When such a system is being designed in urban conditions some calculations of dynamic loads, such as wind pulsation and seismic, are added to the standard calculations. Therefore, it is necessary to solve a number of dynamic problems including the definition of natural frequencies (NF) and forms of natural oscillations (FNO) of tower at its bending fluctuations [9-10]. It is known that in the process of solution of dynamic tasks computational schemes of various levels of approximation can be used. It occurs due to stages of the design and other factors. Thus, at the stage of conceptual design fairly simple schemes can be applied, and then these schemes can be refined. Factor that influenced on the design schemes of wind turbines now is really established practice in our country of designing the system "wind electric set-foundation-base", when the part of the system located above the foundation (the actual wind turbine) is designed in design department of engineering type (eg, "Raduga" in Dubna) and the foundation with the base are designed in building type design organization (for example, Lengidroproekt in St. Petersburg).

Analysis of calculation of projected wind-electric set shows that the design scheme of the system "turbine-foundation-base" at dynamic calculations is divided into the base of the tower at the bottom and the part above the foundation is treated separately from the foundation as a tower console clamped on her soles. Efforts by acting loads, which are acting on the part above the foundation and which are defined in the seals, are transmitted as a load in the form of forces and moments (Fig. 1) for calculating the foundation and the base.

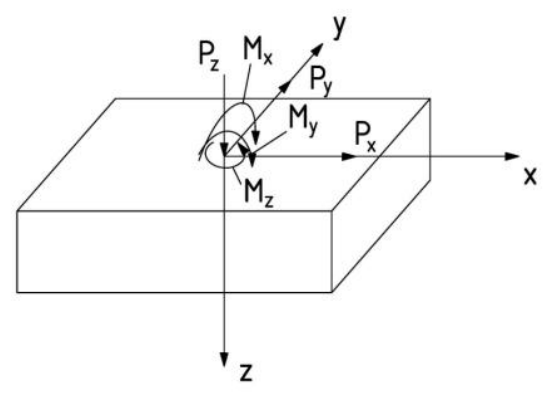

Figure 1. Load in the form of forces and moments in calculation of the foundation and base.

The question of errors, which are associated with the use of a dismembered design scheme, raises. There are no known specific studies on this issue. In [11] it is suggested to estimate the additional inertial loads approximately, these loads are caused because of the fluctuation of the mass of the elements above the foundation of the system and because of deformation of the base by the mass of the foundation. To estimate this additional inertial loads the calculation scheme in the form of a rigid system "wind turbine-foundation (or grillage pile foundation)" on a linearly deformable soil foundation under the action of harmonic loads (resulting from the calculation of the elements above the foundation of the wind turbine) on the gasket face of the foundation are used.

\section{Description of research}

To simplify the research in [11] it is suggested to consider a number of simple tasks to said rigid of the system in the form of steady vertical harmonic oscillations of the load $\mathrm{P}_{\mathrm{z} \text { dyn }}=\mathrm{P}_{\mathrm{z}} \sin \bar{\omega} \mathrm{t}$, rotational oscillations of the load $\mathrm{M}_{\mathrm{z} \text { dyn }}=\mathrm{M}_{\mathrm{z}} \cos \bar{\omega} \mathrm{t}$, and horizontal rotational fluctuations in planes XOZ and YOZ. For example, in the plane XOZ harmonic steady-state oscillations are considered of the loads $\mathrm{P}_{\mathrm{x} \text { dyn }}=\mathrm{P}_{\mathrm{x}} \sin \bar{\omega} \mathrm{t}$ and $\mathrm{M}_{\mathrm{y} \text { dyn }}=\mathrm{M}_{\mathrm{y}} \cos \bar{\omega} \mathrm{t}$. The amplitudes of the loads and frequency $\bar{\omega}=\mathrm{k} \omega$, where $\omega$ is the angular frequency of rotation of the propeller, $\mathrm{k}$ is a certain coefficient, are set.

In this paper we present the results of these calculations which were performed on the Department of structural mechanics and theory of elasticity SPbGPU on the instructions of Lengidroproekt for 
wind turbines such as "Raduga 1000". The calculations are performed in accordance with the recommendations of [11] for disturbing frequencies $\bar{\omega}=\omega$ and $\bar{\omega}=3 \omega$, where $\omega=4.4 \mathrm{~s}^{-1}$ is the angular frequency of rotation of the propeller at the maximum operating speed (42 rev/min). Metal tower of wind turbine has a height of $36 \mathrm{~m}$, the mass of $6116\left(\mathrm{kgf} \cdot \mathrm{s}^{2} \cdot \mathrm{m}^{-1}\right)$, mass moment of inertia of the tower around the axis of the tower, passing through its center of gravity which is perpendicular to the plane of oscillation $\theta_{\phi \mathrm{T}}=0.660 \cdot 10^{6}\left(\mathrm{kgf} \cdot \mathrm{s}^{2} \cdot \mathrm{m}\right)$. The mass of the nacelle with the wind wheel and its moment of inertia about the axis, which is passing through the center of gravity and perpendicular to the oscillation plane, are respectively: $m_{n}=5066\left(\mathrm{kgf} \cdot \mathrm{s}^{2} \cdot \mathrm{m}^{-1}\right) ; \theta_{\phi \mathrm{n}}=0.108 \cdot 10^{6}$ $\left(\mathrm{ktf} \cdot \mathrm{s}^{2} \cdot \mathrm{m}\right)$.

Massive foundation is a square in plan concrete slab with height $h_{f}=3 \mathrm{~m}$ and side length $b_{\mathrm{f}}=11 \mathrm{~m}$. Weight of foundation $\mathrm{m}_{\mathrm{f}}=92500\left(\mathrm{kgf} \cdot \mathrm{s}^{2} \cdot \mathrm{m}^{-1}\right)$, mass moment of inertia around the foundation around the axis of the plate, passing through its center of gravity which is perpendicular to the plane of oscillation, $\theta_{\phi f}=1.002 \cdot 10^{6}\left(\mathrm{kgf} \cdot \mathrm{s}^{2} \cdot \mathrm{m}^{-1}\right)$.

The base is loam with deformation modulus $E=1.5 \cdot 10^{6}\left(\mathrm{kgf} \cdot \mathrm{m}^{-2}\right)$. Stiffness coefficients of the base are calculated by the (Eq. 1-3) of [12]:

$$
\begin{gathered}
\boldsymbol{K}_{z}=\boldsymbol{C}_{\boldsymbol{z}} \cdot \boldsymbol{A}=2.317 \cdot 10^{6} \cdot 121=0.280 \cdot 10^{9}\left(\mathrm{kgf} \cdot \mathrm{m}^{-1}\right), \\
\boldsymbol{K}_{\boldsymbol{x}}=\boldsymbol{C}_{\boldsymbol{x}} \cdot \boldsymbol{A}=1.622 \cdot 10^{6} \cdot 121=0.196 \cdot 10^{9}\left(\mathrm{kgf} \cdot \mathrm{m}^{-1}\right), \\
\boldsymbol{K}_{\boldsymbol{\phi}}=\boldsymbol{C}_{\boldsymbol{\phi}} \cdot \boldsymbol{A}=4.645 \cdot 10^{6} \cdot 1220=5.655 \cdot 10^{9}\left(\mathrm{kgf} \cdot \mathrm{m}^{-1}\right) .
\end{gathered}
$$

The angular frequency of vertical oscillations of the considered rigid system was found to be $52 \mathrm{~s}^{-1}$. When $\mathrm{P}_{\mathrm{Z}}=3900 \mathrm{~kg}$, the additional vertical inertial force in view of the weight of the foundation under steady harmonic oscillation with frequency $\omega=4.4 \mathrm{~s}^{-1}$ was found to be $30 \mathrm{~kg}$. With steadystate horizontal rotational harmonic oscillations with a frequency $\bar{\omega}=3 \omega=13.2 \mathrm{~s}^{-1}$ the additional moment of inertia on the sole of foundation was about $47 \%$ of the set value of the amplitude $\mathrm{M}_{y b}=$ $159300(\mathrm{ktf} \cdot \mathrm{m})$.

An even greater effect of an additional inertial moment on the sole of the pile foundation grillage of the considered type of wind turbine occurs when the first natural frequency of the rigid system is close to the disturbing frequency $\left(\omega_{t}=11.83 \mathrm{~s}^{-1}\right.$ at $\left.\bar{\omega}=3 \omega=13.2 \mathrm{~s}^{-1}\right)$.

In this case, the values of $\mathrm{P}_{\mathrm{xbadd}}$ И $\mathrm{M}_{\mathrm{ybadd}}$ at the sole grillage are close to a predetermined amplitude of loads $\mathrm{P}_{\mathrm{xb}}$ and $\mathrm{M}_{\mathrm{yb}}$ (calculation is given in the report of the department in 1993 to Lengidroproekt).

Thus, if in the designing of wind turbines dissected scheme is used and loads on the foundation are set without inertial forces arising from the mass fluctuations of the foundation due to the deformation of the base, it is necessary to calculate the additional inertial forces using the settlement scheme in the form of a rigid system "wind turbine-foundation (or grillage pile foundation)" on a linearly deformable natural (or pile) basis.

It is also interesting to estimate the effect of partitioning the design scheme in determining the NF and FNO flexural fluctuations of the tower of the wind turbine.

Let's carry out a study, which would help us to evaluate the impact of partitioning the design scheme on the first NF of bending fluctuations of the tower of the wind turbine. We would use for this purpose the simplest calculation schemes when the distribution mass of the tower is replaced by discrete masses (Fig. 2a). In determining the discrete masses based on trapezoidal rule for numerical integration replacing the mass of the nacelle with a wind wheel with a point mass we would obtain (with equal portions of the partition of the tower $\mathrm{r}$ ) the following results: $m_{1}=m_{r}+0.5 \mathrm{~h} \cdot m_{T 1}$, $m_{2}=0.5 \mathrm{~h} \cdot\left(m_{T 1}+m_{T 2}\right)$ etc. With only one portion $(r=1)$, we would obtain the calculation scheme shown in Fig. $2 \mathrm{~b}$, wherein $m_{1}=m_{r}+0.5 \mathrm{~m}_{\mathrm{T}}$ and $m_{2}=0.5 \mathrm{~m}_{\mathrm{T}}$, where $m_{T}$ is a full mass of the tower. Introducing the reinforced concrete foundation (or grillage pile) as a hard array, based on the natural (or pile) linearly deformable base in the latter case we would obtain a system with three degrees of freedom. 
As it was mentioned above, to determine the NF and FNO of bending fluctuations of the tower using partitioned design scheme oscillation of mass of the foundation is not considered, and the tower in section (2) shall be considered as clamped in a rigid or pliable base (Fig. 2c).

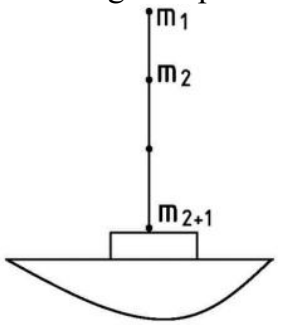

Figure 2a. The simplest calculation scheme when the destribution mass of the tower is replaced by discrete masses.

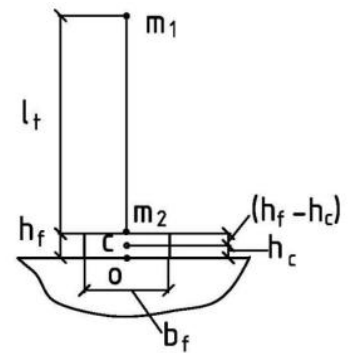

Figure 2b. The calculation scheme with only one portion $(r=1)$.

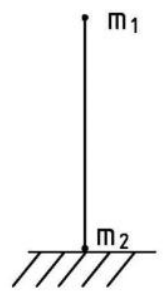

Figure 2c. The calculation scheme with a rigid or pliable base.

With rigid fixing we would have a system with one degree of freedom with mass $m_{1}=m_{r}+$ $0.5 \mathrm{~m}_{\mathrm{T}}$ (scheme 1, a in Tab. 1). More accurate results in determining the frequency $\omega_{1}$ in the case of rigid fixing would be obtained when the equivalent mass, replacing the distribution mass of the tower will be equal 33/140 $\mathrm{m}_{\mathrm{T}}$ [13] (scheme 1, b, Tab. 1).

Let's consider two cases with supple termination in section (2) for comparison. The first one: the oscillation mass $\mathrm{m}_{2}=0.5 \mathrm{~m}_{\mathrm{T}}$ is taken into account (as well as the mass of the foundation), then we would have a system with one degree of freedom (Fig. 1, c) and as we done it before we would consider the reduced mass of the tower in two senses: $0.5 \mathrm{~m}_{\mathrm{T}}$ (scheme 2, a, Tab. 1) and (33/140) $\mathrm{m}_{\mathrm{T}}$ (scheme 2, b, Tab. 1). In the second case, with supple termination in section (2) fluctuation of mass $\mathrm{m}_{2}=\mathrm{m}_{\mathrm{T}}$ would be taken into account (scheme 2, c, Tab. 1) then we would have a system with two degrees of freedom.

To assess the impact of fluctuations of the mass of the foundation on the first natural frequency, let's consider the calculation scheme in view of the foundation of a rigid array. To account for the distributed mass of the tower we should still take the simplest case, when $r=1$. Then for bending fluctuations of the tower and the horizontal rotational fluctuations of rigid foundation in the plane $\mathrm{XOZ}$ we would have a system with three degrees of freedom: horizontal movement of the masses $\mathrm{m}_{1}$ and $\mathrm{m}_{\mathrm{c}}$ and the angle of rotation of the foundation around the center of gravity $(\mathrm{C})$ of the total mass 
$\mathrm{m}_{\mathrm{c}}=\left(\mathrm{m}_{\mathrm{f}}+\mathrm{m}_{2}\right)$, where $\mathrm{m}_{\mathrm{f}}$ is the mass of the foundation, $\mathrm{m}_{2}=0.5 \mathrm{~m}_{\mathrm{T}}$ (Fig. 2,b). Such a calculation scheme with $\mathrm{m}_{1}=\mathrm{m}_{\mathrm{n}}+0.5 \mathrm{~m}_{\mathrm{T}}, \mathrm{m}_{2}=0.5 \mathrm{~m}_{\mathrm{T}}$ and $\theta_{\varphi c}=\mathrm{m}_{1}\left[\mathrm{l}_{\mathrm{T}}+\left(\mathrm{h}_{\varphi}-\mathrm{h}_{\mathrm{c}}\right)\right]^{2}+$ $0.5 \mathrm{~m}_{\mathrm{T}}\left(\mathrm{h}_{\varphi}-\mathrm{h}_{\mathrm{c}}\right)^{2}+\left[\theta_{\varphi \mathrm{f}}+\mathrm{m}_{\mathrm{f}}\left(\mathrm{h}_{2}-0.5 \mathrm{~h}_{\varphi}\right)^{2}\right]$ we would identify as scheme 3 .

Table 1. The values of the first natural frequency fl of bending fluctuations of the tower.

\begin{tabular}{|c|c|c|c|}
\hline \multirow{2}{*}{$\begin{array}{c}\text { Number } \\
\text { of design } \\
\text { scheme }\end{array}$} & \multicolumn{3}{|c|}{ Value of $\mathrm{f}_{1}[\mathrm{~Hz}]$ at } \\
\cline { 2 - 4 } & $\mathrm{E}=\infty$ & $\mathrm{E}=1.5 \cdot 10^{6}\left[\mathrm{kgf} \cdot \mathrm{m}^{-2}\right]$ & $\mathrm{E}=0.6 \cdot 10^{6}\left[\mathrm{kgf} \cdot \mathrm{m}^{-2}\right]$ \\
\hline $1, \mathrm{a}$ & 1.10 & & \\
$1, \mathrm{~b}$ & 1.20 & & \\
$2, \mathrm{a}$ & & 1.05 & 0.97 \\
$2, \mathrm{~b}$ & & 1.15 & 1.06 \\
$2, \mathrm{c}$ & & 1.05 & 0.97 \\
3 & & 1.04 & 0.94 \\
\hline
\end{tabular}

The Tab. 1 shows the values of the first natural frequency $f_{1}$ (in hertz) of bending fluctuations of the tower for the considered design schemes of one variation of the wind turbine. The calculations were performed for the following values of the masses of elements of the design scheme: the mass of the nacelle with the wind wheel $\mathrm{m}_{\mathrm{r}}=5066\left(\mathrm{kgf} \cdot \mathrm{s}^{2} \cdot \mathrm{m}^{-2}\right)$, the mass of the tower (only pipe) $\mathrm{m}_{\mathrm{T}}=$ $4534\left(\mathrm{kgf} \cdot \mathrm{s}^{2} \cdot \mathrm{m}^{-1}\right)$, mass of square in plan concrete slab with a side $\mathrm{b}_{\mathrm{f}}=11 \mathrm{~m}$, and a thickness $\mathrm{h}_{\mathrm{f}}=3 \mathrm{~m}, \mathrm{~m}_{\mathrm{f}}=92500\left(\mathrm{kgf} \cdot \mathrm{s}^{2} \cdot \mathrm{m}^{-1}\right)$. The basis for the foundation is loam with the deformation modulus $\mathrm{E}=1.5 \cdot 10^{6}\left(\mathrm{kgf} \cdot \mathrm{m}^{-2}\right)$. The base was considered as Winkler and the characteristics of its stiffness $(\mathrm{Cz}, \mathrm{C} \phi, \mathrm{Cx}, \mathrm{k} \phi, \mathrm{kx})$ under the sole of foundation were calculated by the formulas (4) and (5), (9), (10) in [12].

Comparing the values of $\mathrm{f}_{1}(\mathrm{~Hz})$ for the calculation schemes $1, \mathrm{a} ; 2, \mathrm{a} ; 2, \mathrm{c} ; 3$, it is seen that for the base with module $\mathrm{E}=1.5 \cdot 10^{6}\left(\mathrm{kgf} \cdot \mathrm{m}^{-2}\right)$ and a reinforced concrete foundation of these sizes an account of deformation of the base and of the mass of the foundation has a very little effect on the lowest natural frequency of bending flrctuations of the tower. Therefore, in this case it is permissible to use the calculation scheme only of the part above the foundation in calculating $\omega_{1}$ and $f_{1}\left(f_{1}=\right.$ $\left.\omega_{1} / 2 \pi\right)$ and consider the cross-section (2) as rigid or resiliently deformable.

The calculations has been done for $\mathrm{fl}(\mathrm{Hz})$, when the soil deformation modulus was decreased by 3 times, to investigate the effect of increasing the compliance of the base. $\mathrm{E}=0.5 \cdot 10^{6}\left(\mathrm{kgf} \cdot \mathrm{m}^{-2}\right)$ (minimum value is shown in Tab. 3 of Annex I of [14]). Assume that the size of the foundation and the coefficient $b_{0}$ in the equation (4) in [12] remain unchanged. Then, in accordance with a decrease of E by three times all values of $\mathrm{C}_{\mathrm{z}}, \mathrm{C}_{\varphi}, \mathrm{C}_{\mathrm{x}}, \mathrm{k}_{\varphi}, \mathrm{k}_{\mathrm{x}}$ decrease by three times too, and the coefficients of compliance $\delta_{\mathrm{xc}}=1 / \mathrm{k}_{\mathrm{x}}$ and $\delta_{\varphi c}=1 / \mathrm{k}_{\varphi}$ increase in three times.

Comparing the results of calculations for schemes $1, a ; 2, a ; 2, c ; 3$ (Tab. 1) it is seen that the transition from the rigid base $(\mathrm{E}=\infty)$ to very compliant (minimum value of $\mathrm{E}$ in Tab. 3 of Annex I of [14]) $E=0.5 \cdot 10^{6}(\mathrm{kgf} \cdot \mathrm{m}-2)$ changes the value of $\mathrm{f}_{1}$ by about $13 \%$. Accounting of mass of foundation with more pliable base decreases the value of the first frequency much greater than the more rigid base (scheme 2, a; 2, c; and 3).

Some calculations related with wind turbines would be held in future in a view of:

- geometric nonlinearity [15],

- thin-walled cross-sections [16],

- sustainability [17],

- elastic plasticity [18].

The held calculations are relevant for the diversity of renewable energy sources which are actively developing in our time [19-23]. 


\section{Conclusions}

It is proved that the inclusion of deformation of the base and the mass of the foundation has a very little effect on the lowest natural frequency of bending fluctuations of the tower. The transition from the rigid base to very pliable base changes the value of $\mathrm{fl}$ by about $13 \%$. The studies show that the use of dissected calculation scheme for determining the load on the foundation and the base, and the natural frequencies and shapes of bending fluctuations of the tower is allowed, especially at the initial stage of designing wind turbines. In this case unaccounted inertial forces associated with the fluctuation of the system due to the deformation of the base can be approximately obtained by the rigid system "Wind Turbine + foundation (or grillage pile foundation)" on a natural (or pile) linearly deformable foundation.

The first natural determined frequency at a rigid termination on the sole of the tower should be lowered in view of studies, shown in Tab. 1.

\section{References}

1. N. Vatin, N. Lavrov, A. Shipilov, Procedia Engineering, 117 (1), 374-380 (2015)

2. O. V. Shepovalova En. Proced., 74, 1551-1560 (2015)

3. K.N. Shxinek, A.I. Alximenko, A.A. Alximenko, Altern. energ. i ekol., 11, 29-35 (2014)

4. T.V. Miroliubova, Vest. Perm. un. (Ekon.), 4(7), 78-86 (2010)

5. Q.S. Li, F.B. Chen, Y.G. Li, Y.Y. Lee, J. of Wind Eng. and Ind. Aerod., 116, 70-82 (2013)

6. Tao Ma, Hongxing Yang, Lin Lu, Jinqing Peng, Appl. En., 160, 728-736 (2015)

7. Ayşenur Erdil, Hikmet Erbiyik, Proced. - Soc. and Beh. Sc., 207, 669-679 (2015)

8. E. V. Solomin, Vest. Iuj.-Ural. gos. un. (Ekon. i men.), 20 (196), 32-36 (2010)

9. Fahad jamil, Saad bin zia, Parvez ali abbasi, Moiz ansari, To Study of Wind Resistant Stability of Tubular Wind Turbine Tower (NED university of engineering and technology, Karachi, 2012)

10. Ching-Wen Chien, Jing-Jong Jang, Proc. of the Sev. As.-Pac. Conf. on Wind Eng., 8 (12), 1-8 (2009)

11. I.A. Konstantinov, Yu.A. Ippa, N.V. Miklashevich, Raschetnye sxemy oistemy "VEU-fundamentosnovanie" dlya opredeleniya raschetnyx nagruzok na fundament $i$ osnovanie $i$ amplitud ix kolebanij (Predso-93, 1994).

12. SP 26.13330.2012. Updated edition of SNiP 2.02.05-87 Foundation of machine with dynamic loads

13. S.P. Timoshenko. Kolebaniya v inzhenernom dele (Stroyizdat, Moscow, 2006)

14. SP 22.13330.2011. Updated edition of SNiP 2.02.01-83* Foundations of buildings and constructions.

15. A.V. Yavarov, Zhil. stroy., 5, 51-54 (2013)

16. Arash Sahraei, Liping Wu, Magdi Mohareb, Thin-Wall. Struct., 89, 212-226 (2015)

17. D.A. Kushova, Appl. Mech. and Mat., 617, 181-186 (2014)

18. B.E. Melnikov, A.S. Semenov, ZAMM, 76 (2), 615-616 (1996)

19. J. Ćetković, S. Rutešić, M. Zarković, M. Knežević, N. Vatin, Procedia Engineering, 117 (1), 780 790 (2015)

20. Cheng-Dar Yue, Chung-Sheng Chen, Yu-Chen Lee, Ren. En., 86, 930-942 (2016)

21. Dany Perwita Sari, Wida Banar Kusumaningrum, En. Proced., 47, 29-36 (2014)

22. Z. Bonić, G.T. Curčć, M. Trivunić, N. Davidović, N. Vatin, (2015) Procedia Engineering, 117 (1), 424-435 (2015)

23. Z.Popović, L. Lazarevic, N. Vatin, Procedia Engineering, 117 (1), 846-853 (2015) 